\title{
Living my narrative: Storying dishonesty and deception in mental health nursing
}

\section{Abstract}

This paper proceeds from MacIntyre's moral philosophical perspective of individual human lives constituting unified narratives, in the context of co-evolving framing and guiding master narratives. This perspective accords specific episodes in people's lives the status of significant component parts of their developing, storied and enacted individual histories. From this philosophical base, autoethnographic principles will be employed in providing accounts from my own professional life narrative strand as a mental health nurse educator that speak to the issue of institutionalised dishonesty and deception in mental health nursing education and practice. On the basis of my pre-existing experience of publishing in nursing journals and scholarly identity, my argument will proceed from contesting the idea of an imagined stable foundational professional ethos underpinning mental health nursing practice, against which to judge professional dishonesty and deception. Using illustrative, relatively recent short stories, drawn from my lived-experience base as a mental health nurse educator, I will argue throughout at implicit and explicit levels that dishonesty and deception are always an inevitable part of the lives of mental health nurses and their educators. This is because of a constant gap between the nursing rhetoric and ideology that both groups espouse and how they actually behave on a day-to-day, mundane level, in and out of work and classroom practice. This gap shows up the public front of what mental health nursing is supposed to be about as dishonest and deceitful window dressing. I will assert that the use of more first person, lived experience accounts in mental health nursing teaching and publication are important educational resources in reducing this gap at professional practice, academic and informal levels. Such storied accounts may also be useful in moving nurses and their educators 
towards more morally and ethically sensitive, and reflexively-attuned positions around what they talk and write into existence.

Keywords: Life Story, Mental Health, Nursing, Nursing Philosophy, Narrative, Narrative Ethics. 


\section{Introduction}

From a moral philosophical perspective, Maclntyre (1985) argues that a human life is a unified narrative embedded in a plurality of other narratives. In this context, a person's life should not be seen as separate from the specific roles they assume throughout the time between their birth and death. Behaviours that form part of a unified narrative only make sense if human intentions are seen to be, or can be made, intelligible, and such behaviours depend on and will change according to shifting contexts of meaning grounded in specific life circumstances. In Maclntyre's terms, meaning always derives from sets of pre-existing and subsequently developing narratives which, as metanarratives, provide templates for guiding the storied lives of individuals in their social and material worlds.

This inevitably means that people extend, nuance and are caught up in - often in contradictory ways - a messy plurality of narratives that dramatically co-evolve with their lives, in an open-ended and unpredictable fashion. Such a process of continually storying and re-storying lives ends for individuals with death. In their absence from life's stage, the broader narratives in which they were embedded continue to co-evolve and mutate according to shifting historical contingencies and circumstances.

In a dynamic and constantly shifting way, some metanarratives are implicated in implicitly or explicitly informing individual life stories and, equally, some are resisted against. From this perspective, all human actions that form particular extended episodes, or strands of people's lives are enacted, narrative histories, 'both of the individual concerned and of the settings in which they act and suffer' (MacIntyre 1985, 211). Individuals are thus both agents and coauthors in and of all aspects of their enacted lives, but are always only partially responsible 
for shaping their personal narratives. Their stories can be interrupted, hijacked and co-opted into the stories of others, at individual, organisational and institutional levels, often in ways beyond their control.

Maclntyre's philosophy complements and provides depth for the activity of contemporary autoethnographic scholars. Eschewing the metanarrative of scientific objectivity, autoethnographers celebrate the contributions they make to social and human scientific inquiry on the basis of their lived-experience of episodes in their worlds as socially-, materially- and culturally-situated speakers (Richardson, 1997).

The above philosophical and social inquiry platform informs an extended episode in my life: I will describe in this paper my simultaneous ongoing storied engagement with and estrangement from mental health nursing education and practice. I will do so in the context of the institutionalised deception and dishonesty I see and experience in the gap between nursing rhetoric and ideology and how nurses and their educators actually behave on a dayto-day, mundane level, in and out of work and classroom practice. In so doing, I will formally contribute to the developing story of my professional life as a nurse educator. Moreover, in deploying autoethnographic principles in constructing my paper, I will aspire to theoretical and methodological coherence and make a substantive contribution to my oeuvre within one of the significant storied communities to which I belong: autoethnographic inquiry (Short et al., 2013). 


\section{The invitation}

In late November, 2015, I receive an email inviting me to consider contributing to a special issue of the journal, Nursing Philosophy, devoted to 'Dishonesty and Deception in Nursing'. I read the flyer and, on further invitation, speak to one of the guest editors. I express my concern that, although I am tempted to contribute a manuscript, as a longstanding member of editorial boards and as a past peer reviewer and article writer, I am in two minds about doing so. I tell him that I have grown wary of the editorial and representational practices, and article construction rules and expectations, that authors are faced with when they prepare qualitative research articles for mainstream nursing journals. In this context, I specifically mean that these practices, rules and expectations, while working well for papers informed by postpositivist and conventional qualitative methodologies, militate against the novel and unusual forms of article construction proceeding from the experimental, poststructural, 'messy text' and autoethnographic qualitative designs that I've long been associated with (Short et al., 2013). I share with him my belief that, in a kind of elective affinity with health and mental healthcare at a clinical level, these practices, rules and expectations serve to maintain a status quo of normativity in privileging orthodox methodologies.

In my view, this is in itself a form of deception to the extent that these methodologies promote an ideological view of the world that rests on a fixed categorical divide between professional and patient or user identities, and normative practices. This conflicts with the critical methodological approaches I work within that both celebrate more messy, lived experience-based, conflated professional and user identity positions, and critique ontoepistemological and practice orthodoxies. His response is reassuring however and, following 
a further positive response from him after he read one of my recent autoethnographic papers, I proceed.

As I work on this article, I read and re-read the flyer and the paper that inspired this special issue call. I am struck by the opening lines of the foreword to Lying to Ourselves (Wong and Gerras, 2015): 'One of the hallmarks of a true profession is its ability to assess and regulate itself, especially with respect to adherence to its foundational ethos...' It increasingly seems to me that both the flyer and the paper are based on bounded rational assumptions. From a storied life perspective, the idea of apparently desirable professional goals relating to an imagined fixed and stable foundational ethos of a profession falls down on the basis of the probability that ethical bases constantly mutate. In a dynamic way, they are likely to become regularly re-inscribed within the shifting formal and informal instrumental rational goals, and background cultural narratives, governing profession identity and behaviour at different points in space and time. This happens in a messy plurality of ways by the various stakeholders involved in 'storying' the life of a profession.

So, with regard to mental health nursing, 'instrumental rationality' is always multiply nuanced, simultaneously serving the symbolic needs of 'evidence-based practice', local custom and practice, broader cultural influences, biomedicine and social control, and the maintenance of ongoing social relationships, in contradictory ways. This state of affairs will inevitably function to undermine the coherence and integrity of any attempt to present a public front of an overarching stable metanarrative of a profession, and is well illustrated in the following accounts. These illustrate my growing discontent around teaching and associating with mental health nurses over the last two decades. 


\section{Championing hybrid scholarship}

In recent years, I have had to struggle with teaching mental health nurses according to a policy and professional driven curricula at odds with my developing scholarship in narrative inquiry (Grant et al., 2011, 2013), narrative competence (Corbally and Grant, 2016), relational autoethnography (Grant et al., 2015) and demedicalizing mental health (Grant, 2015).

I am one of a small number of people committed to championing reflexive subjective, first person, lived-experience and autoethnographic writing in mental health. My scholarship aims to provocatively expose the gaps between mental health nursing rhetoric and ideology (in institutional terms, what nursing is supposed to be about) and the lived experience of survivors and practitioners - the latter always giving the lie to the former.

My work does not support or represent absolute categorical distinctions between mental health 'practitioners', 'users', 'survivors' and 'academics', since I embody all of these identities simultaneously in my writing and teaching. Borrowing a term from postcolonial scholarship, I maintain a hybrid standpoint position as a mental health academic-expractitioner-survivor of the UK institutional mental health system (Grant et al., 2015). These personal descriptors shift around the hyphens, depending on which aspect or aspects of my identity, or which particular story of myself and my concerns, I'm privileging in my academic presentations and writing at any one time.

So, I find myself constantly teaching and writing against the grain of the mental health nursing curricular content and clinical practice, both of which rest on categorical distinctions between 
nurses and service users or patients, and a knowledge base that supports these distinctions. This lack of fit between my evolving scholarly identity and onto-epistemological curricular and practice assumptions has led me to develop a growing antipathy towards the institution of mental health nursing. This has grown steadily, year on year, more especially since my negative experiences as an in-patient in an acute mental health ward ten years ago (Grant, 2011).

\section{The dinner party}

I thus experienced the contradictions between professional and educational rhetoric and displays of disparaging and 'othering' accounts of students and qualified staff about the people they purport to be in the business of caring as deeply offensive. They could be talking about me in my days as an acute ward patient, and some once were. However, I am by no means free of blame in this regard.

At a recent social event, I spent the evening with a group of mental health nurse educators. Over dinner, we shared nostalgic stories of our times as student mental health nurses back in the 1970s and 80s. One of my companions described the first time he'd met a patient after the latter's recent lobotomy. His graphic description of how this seemed to change the shape of the patient's head and facial features is met with guffaws by my companions. I joined in with the laughter.

Later at my home, I became pre-occupied with lots of conflicting thoughts and feel a mixture of mild self-disgust and bitter irony over the fact that my collusion in storying patients in 'othering' and abusive ways sat badly with my narrative ethical standpoint and current 
scholarly purpose. I had also shared one or two patient anecdotes, breaking my own rules in the interests of maintaining bonhomie, and co-constructing a group identity through the use of humour.

This account is illustrative of my being constantly troubled by a question that never goes away for me: why are many mental health nurses and others working in mental health, myself included from time-to-time, complicit with such practices?

\section{From Arendt to Socrates: thoughtlessness and the banality of evil}

Wong and Gerras (2015) describe the mismatch between public adulation of US military personnel as moral exemplars and their institutionalised engagement in deceitful practices that escape the public gaze. Their writing resonates with my growing antipathy towards mental health nursing. This is based on the gap between my lived-experience as an educator and past service user and the ways in which mental health nursing publicly and professionally promotes itself as a trustworthy institution at all levels, in terms of its rituals, principles, assumptions and related educational and practice activities.

The fact that the precise nature of the forms of professional complicity with reprehensible cultural practices shift as a function of time and place demands serious sociocultural consideration. In regard to nursing, Roberts and Ion (2014) recently spoke to the need for such critical analysis from an Arendtian perspective. Arendt (1992) asserted that organisational socialisation and habituation to their engagement in such practices leaves many of the people involved, by default as complicit perpetrators, untroubled. Her 'banality of evil' argument is that the mass participation by otherwise ordinary people in acts that later 
attract retrospective social and cultural condemnation does not imply an essentially wicked character on the part of most of the people involved.

However, in the wake of scandals perpetrated in the name of care, whether at a major, large scale level or in more minor and banal, but no less insidious, forms of day-to-day routinised abuses, I often witness nurses, nurse educators and others defensively invoking the 'few bad apples' argument. They do this in spite of current literature that points to the need to consider these issues in ways that do justice to their systemic and social psychological complexities (Payley, 2014; Traynor et al., 2014). 'Bad apple' understandings represent a variant of 'othering'; a kind of verbal NIMBY (not in my backyard) stance, where rogue individuals or practice locations are implicitly storied as 'not like us', not representative of the general mass of ethically attuned, caring nurses. Arendt (1971) suggested the opposite: that participation in such events is a constant possibility for everyone.

She argued that this is because of a tendency for 'thoughtlessness' to become institutionalized on a large scale. In her terms, thoughtlessness is a kind of routinized inability to think that serves the interests of instrumental rationality. Instrumental rationality is characterised by unquestioning adherence to cultural rules and expectations in order to achieve maximal organisational efficiency in relation to cultural goals. From an Arendtian position, Roberts and Ion (2014) argue quite rightly that neoliberal instrumental rationality has become increasingly prevalent in our healthcare organisations in recent years, informing and shaping the activities and professional identities of contemporary nurses of all branches. However, from a storied life perspective, nurses' complicity with such practice imperatives 
has arguably taken many shifting culture- and time-specific forms since the advent of institutional psychiatric practice.

I find myself allied with Roberts and lon in my longstanding concern about the function of neoliberal instrumental rationality in the UK and elsewhere in compromising undergraduate mental health nursing curricula (Grant 2014). There is a continual tension between explicit higher educational curricula that might be delivered provocatively on the basis of Socratic discussion and implicit service curricula associated with training in the service of organisational business-as-usual (Grant and Radcliffe, 2015).

In this context, Arendt (1971) distinguished between those who are socialised into and engage in institutionally- and organisationally-sanctioned thoughtlessness and those who refuse this. Positioning Socrates as a seminal role model in this regard, she advocated a critically interrogative approach to that which is taken for granted in life (and by implication and extension current mental health nursing higher education and practice). This functions to disrupt habituated thoughtless participation in morally reprehensible practices. In such an approach, thinking, writing and related teaching are positioned as acts of resistance; as embodied, enacted ethics in the service of storying morally desirable practices into existence.

\section{The lecture}

Recently, I prepared for a lecture that I was scheduled to present to a group of second year mental health nursing students at a university in a different geographical location from where I live and work. While preparing, I was aware of a growing background anxiety in anticipation of the event. I was particularly concerned about a sound clip on my powerpoint, which was 
of a reading from one of my autoethnographies of my time spent as a patient in an NHS acute mental health ward a decade or more ago (Grant, 2011). The clip described the content of the abusive voices I heard while psychotic, potentially suicidal and under close observation.

Before I played the clip, I set the contextual scene for the students. This was around mainstream institutional psychiatry's business-as-usual style of responding to people who hear voices, which endorses disrespectful and unhelpful mental health nursing attitudes and interactions with service users.

Without identifying where the clip came from or the identity of the person being described, I turned it on:

...The man in the sideroom is $52 \ldots$ He has had a prolonged episode of hearing voices and (experiencing) false beliefs... The voices appear to come from outside of him and are loud. They shout:

'Kill yourself, you bastard...You worthless heap of shit'....

(Grant 2011, 126)

As I anticipated, the swear words triggered defensive laughter among some of the younger students, betraying their discomfort. When this died down I asked for their responses to the sound clip. These were informed exclusively by the disease paradigm, such as 'I' $d$ feel sorry for this man as he's clearly ill', and 'these are symptoms of severe mental illness and he needs treatment'. Some of the students were still in their teens and, perhaps understandably, 
expressed fear and uncertainty around the best ways to engage with someone in that circumstance.

I then disclosed to the students that I was describing my own lived-experience, and that during my time on the acute ward none of the nurses there seemed interested in spending time or talking with me, apart from observing me in silence.

At that point, an earnest looking student mental health nurse, who looked to be a little older than the rest of the group and had been attentive to me since the start of my lecture, spoke up. 'We are taught to be careful not to engage with people's hallucinations and delusions, because doing so serves to reinforce them.' I found myself bristling a little, partly in response to his biomedical vocabulary in contrast to mine, and because his comment betrayed the normative and anachronistic assumptions informing his education. With measured authority, I replied: 'What you're being taught is $20-30$ years out of date. The opposite is in fact regarded as the most helpful thing to do these days.'

I advised him and the others to read psychosocial paradigm work from Kinderman (2014), Read and Dillon (2013) and my edited narrative work (Grant et al., 2011), around the need to engage with people and their accounts of their voices, their beliefs about where these come from and how they are triggered, their significance in terms of early traumas, and the role of institutional psychiatric settings in compounding rather than alleviating such problems. I talked about Jacqui Dillon's work in the Hearing Voices UK network (Read and Dillon, 2013) and the more formal cognitive therapy approaches for voice hearing and false beliefs 
(Morrison et al., 2003), again including my own edited work in this area, written by my excognitive therapy students (Mills,2008; Mulhern, 2010).

I invited the group to make further, final comments on the audio clip. A student asked 'it must be difficult for you, to talk about your own experiences like that?' Aware of the mixture of empathy and social judgement implicit in her question, I replied: 'writing and talking about my experiences is not difficult, as I've managed to integrate them into my personhood over the years and I believe it is ethically appropriate to share them in the context of my narrative work and hybrid identity position...'. I later thought that had I been a little less controlled in my response, I could have added 'sharing my experiences is not the problem for me. The predictable, anachronist and judgemental reactions of people in, or preparing to take their place in, the mental health professions is, however'.

\section{Making sense of my stories}

In making sense of the experiences and accounts I have described above from the perspective of storied life and identity, I am struck by a number of issues. To borrow from Goffman (1959), my stories describe the tensions between frontstage and backstage professional narrative enactment and the ways in which I am inevitably implicated in these tensions - true as much for the US military (Wong and Gerras, 2015) as it is for storying user and professional lives within mental health nursing practice and education.

As meta-autoethnography (using autoethnographic principles to describe my previously published autoethnographic and related work and identity), I have storied myself in this 
paper, as I have in most of my writing, as a credible and well-published scholar in critical and marginal, lived-experience onto-epistemological domains. This in itself is a rhetorical representational device that sometimes seduces me, and may seduce possible readers, into believing that I mostly occupy the narrative moral high ground.

By describing how I write and teach against mainstream institutional mental health nursing educational, clinical and representational practices, I have written myself squarely and rather excitingly (for me at any rate) into new and emerging critical paradigms. My professional life story style is of expressing antipathy to normative, anachronistic and thoughtless rulefollowing practices, while being immersed in them as a mental health nurse educator. This positions me as a kind of micro- and macro-organisational trickster, 'fifth columnist' or latter day knight-errant figure, whose assumed and combative scholarly role is to expose morally questionable off-duty and classroom practice. This is of course fully justifiable in terms of my autoethnographic storied identity and purpose, which is to use storytelling critically, politically and strategically in the service of resistance to dominant and hegemonic, but ultimately oppressive, cultural practices.

But what drives all of these aspects of my storied life? Since my days of being diagnosed and treated in the UK institutional psychiatric system, I am constantly sensitised and resistant to what I have previously described as 'narrative entrapment' (Grant et al., 2015): being stuck in the unwanted and unwelcome stories that mental health professionals, including nurses, may tell about me. And yet, ironically, I employ othering representational practices in order to 'story up' my narrative virtue. I do so in the service of constantly policing the boundaries and 
integrity of my own lived story in a landscape of competing narratives which, although contested and rejected by me, I am always written into in various ways.

\section{Conclusion}

That said, the utility of autoethography in critiquing professional cultures from an applied philosophical position has, I believe, much to offer in the ongoing storying of life. Publishing the lived experiences of nurses and their educators caught in the tensions between professional and public rhetoric and subjectively experienced lived-deception and dishonesty can contribute greatly to a developing metanarrative of nursing as an increasingly more transparently and coherently honest discipline.

Dishonesty and deception are, I believe, always and inevitably part of our lives in terms of our storied inscription within contradictory and constantly co-evolving and mutating master narratives. I read my own professional nurse educator life as a continual striving to negotiate with some integrity my own story through such a landscape, where sanitised public- and professionally-facing ideological rhetoric co-exists with implicit organisational narratives (Richardson, 1997; Smircich, 1983). The former, more formal set is evident in policy, professional and research texts, while the less formal latter is enacted in the conversations and actions of nurses in and out of work and classroom time. The former set usually aspires to a level of professional and, currently, evidence-based practice that is generally not realised in an adequate way in either practice or classroom. The latter betrays the local organisational and wider cultural values-based, often anachronistic, forms of custom and practice, which constantly undermine the former. I consequently experience ideological rhetoric and implicit organisational narratives as riven with dishonesty and deception. 
Both are explicitly othering, based on an assumed and constantly reified divide between professional nurse and disordered service user. Further, both constitute variants of instrumental rationality in that they function simultaneously, in an incoherent way, to socialise and discipline nurses into adherence with mismatched goals. Nurses have to balance the competing demands of frontstage professional and public impression management while fitting in what is organisationally, culturally and socially valued in their local work setting.

It seems to me that more first person, lived-experience accounts will also bring into sharper focus the issue of narrative ethics (Adams, 2008), in the tensions and contradictions between and within formal and informal mental health nursing representational practices. In Arendtian terms, storytelling is arguably an important and much needed Socratic educational tool in reducing the gap between nursing rhetoric and lived experience. This may help nurses and their educators develop the necessary levels of critical reflexivity to more readily challenge the forms of curricular-retarding thoughtlessness that they are socialised into, and better sensitise them to the constantly incoherent nature of their storied location and identities. In this regard, clearly some stories are always going to be more morally and ethically appealing than others. In reducing the gap between what we practice and what we preach, we need to increase our sensitivities around what we talk and write into existence.

\section{References:}

Adams T. (2008) A Review of Narrative Ethics. Qualitative Inquiry, 14(2), 175-194.

Arendt H. (1971) Thinking and moral considerations: a lecture. Social Research, 38, 417-466. 
Arendt H. (1992) Eichmann in Jerusalem: A Report on the Banality of Evil. Penguin, New York.

Corbally M. \& Grant A. (2016) Narrative competence: A neglected area in undergraduate curricula. Nurse Education Today, 36, 7-9.

Goffman E. (1959/1971) The Presentation of Self in Everyday Life. Penguin, Harmondsworth.

Grant A. (2011) Performing the Room: In: Our Encounters with Madness (eds. A. Grant, F. Biley \& H. Walker) pp. 125-130. PCCS Books, Ross-on-Wye.

Grant A. (2014) Neoliberal higher education and nursing scholarship: Power, subjectification, threats and resistance. Nurse Education Today, 34, 1280-1282.

Grant A. (2015) Demedicalizing misery: Welcoming the human paradigm in mental health nurse education. Nurse Education Today, 35, e50-e53.

Grant A. \& Radcliffe M. (2015) Resisting Technical Rationality in Mental Health Nurse Higher Eduction: A Duoethnography. The Qualitative Report (TQR), 20 (6), Article 6, 815-825. http://www.nova.edu/ssss/QR/QR20/6/grant6.pdf

Grant A., Biley F. \& Walker H. (eds) (2011) Our Encounters with Madness. PCCS Books, Rosson-Wye.

Grant A., Haire J. \& Stone B. (eds). (2013) Our Encounters with Suicide. PCCS Books, Ross-onWye. 
Grant A., Leigh-Phippard H. \& Short N. (2015) Re-storying narrative identity: a dialogical study of mental health recovery and survival. Journal of Psychiatric and Mental Health Nursing, 22, 278-286.

Kinderman P. (2014) A Prescription for Psychiatry. Why We Need a Whole New Approach to Mental Health and Wellbeing. Palgrave Macmillan, Basingstoke and New York.

Maclntyre A. (1985) After Virtue. A Study in Moral Theory. Second Edition. Duckworth, London.

Mills J. (2008) Wade Eppeley and the liquid faced masks. A cognitive behavioural case formulation for distressing psychosis. In: Assessment and Case Formulation in Cognitive Behavioural Therapy (eds. A. Grant, M. Townend, J. Mills \& A.Cockx) pp. 173-181. SAGE Publications Ltd., London.

Morrison A., Renton J., Dunn H., Williams S. \& Bentall R. (2003) Cognitive Therapy for Psychosis: A Formulation-Based Approach. Brunner-Routledge, Hove.

Mulhern R. (2010) Psychosis. In: Cognitive Behavioural Therapy in Mental Health Care. Second Edition. (eds. A. Grant, M. Townend, R. Mulhern \& N. Short) pp. 119-141. SAGE Publications Ltd., London.

Payley J. (2014) Cognition and the compassion deficit: the social psychology of helping behaviour in nursing. Nursing Philosophy, 15, 274-287. 
Read J. \& Dillon J. (2013) Models of Madness. Second Edition. London and New York, Routledge.

Richardson L. (1997) Fields of play: Constructing and academic life. Rutgers University Press. New Brunswick, NJ.

Roberts M. \& Ion R. (2014) Thinking critically about the occurrence of widespread participation in poor nursing care. Journal of Advanced Nursing, 71(4), 768-776.

Short N., Turner L. \& Grant A. (2013) Contemporary British Autoethnography. Sense Publishers, Rotterdam.

Smircich L. (1983) Concepts of culture and organizational analysis. Administrative Science Quarterly. 28, 339-358.

Traynor ., Stone K., Cook H., Gould D. \&Maben J. Disciplinary processes and the management of poor performance among UK nurses: bad apple or systemic failure? A scoping study. Nursing Inquiry, 21(1), 51-58.

Wong S. \& Gerras S.J. (2015) Lying to Ourselves: Dishonesty in the Army Profession. U.S. Army War College Strategic Studies Institute., United States Army War College, PA Press, Carlisle Barracks. 
